\title{
Discounting in Economic Evaluations
}

\author{
Arthur E. Attema $^{1} \cdot$ Werner B. F. Brouwer ${ }^{1} \cdot$ Karl Claxton $^{2}$
}

Published online: 19 May 2018

(C) The Author(s) 2018

\begin{abstract}
Appropriate discounting rules in economic evaluations have received considerable attention in the literature and in national guidelines for economic evaluations. Rightfully so, as discounting can be quite influential on the outcomes of economic evaluations. The most prominent controversies regarding discounting involve the basis for and height of the discount rate, whether costs and effects should be discounted at the same rate, and whether discount rates should decline or stay constant over time. Moreover, the choice for discount rules depends on the decision context one adopts as the most relevant. In this article, we review these issues and debates, and describe and discuss the current discounting recommendations of the countries publishing their national guidelines. We finish the article by proposing a research agenda.
\end{abstract}

Arthur E. Attema

attema@eshpm.eur.nl

1 Erasmus School of Health Policy and Management, Erasmus University Rotterdam, P.O. Box 1738, 3000 DR Rotterdam, The Netherlands

2 Centre for Health Economics, University of York, York, UK

\section{Key Points for decision makers}

Most national pharmaceutical guidelines prescribe equal discounting of costs and effects without proper justification, or on the basis of theoretical arguments that do not necessarily bear practical relevance.

Discount rates depend heavily on developments in opportunity costs of healthcare spending (marginal productivity of spending) and in the consumption value of health, but these measures lack empirical estimations.

Care should be taken to avoid the practice of double discounting, which can cause severe misallocations of healthcare resources.

\section{Introduction}

Often, the costs and benefits considered in a health economic evaluation are not only incurred in the current year, but materialize beyond the present. For the valuation of costs and benefits in the context of an economic evaluation, their timing is relevant because people generally value future costs and effects less than current costs and effects and their value diminishes the more distant in the future they occur. Hence, economic evaluations need to adjust the value of costs and benefits for the time at which they occur, a technique known as discounting. While the procedure of discounting may seem a technical method to some, its effects on final outcomes may be substantial [1-3]. 
Very few economic evaluations of healthcare interventions do not require discounting of costs and effects. Even a one-shot intervention that immediately reduces mortality will still produce most effects in the future because the prevented deaths reflect (quality-adjusted) life-years occurring in future periods. For other interventions, which are designed to reduce the risk of future health shocks, such as influenza shots or primary prevention of stroke, discounting is even more relevant [4]. Hence, in many interventions the intertemporal nature of economic evaluations is obvious, which makes the use of discount rates necessary. Together with the impact of discounting and different discounting approaches [3], this underlines the importance of appropriate discounting rules in economic evaluations and guidelines.

However, discounting in economic evaluations is not straightforward and has proven to be controversial. For instance, the analyst has to choose a particular discount model (e.g., constant discounting or hyperbolic discounting), the height of the discount rate(s) used, and whether to discount costs and effects at the same rate. These questions have received quite some attention in the literature.

In this article, we highlight some of these ongoing issues and describe the current state of affairs. To start with, Sects. 2.1 and 2.2 provide a brief history of discounting practices. Section 2.3 continues with a discussion of normative vs. positive stances, while Sect. 2.4 considers the sources of discount rates. Section 2.5 describes equity issues related to discounting, and Sect. 2.6 raises the problem of double discounting. In Sect. 3, we summarize the current discounting practice for the countries with public national guidelines on this matter. Section 4 then discusses different approaches to discounting practices, and the article ends with a research agenda in Sect. 5 and a short conclusion in Sect. 6.

\section{Discounting and Different Approaches}

\subsection{Discounting of Costs and Health Effects: Brief History}

Some people find it difficult to understand why future costs and (especially) health should be discounted at all and have a lower value than current costs and health effects. There are several reasons to discount future outcomes, one of which is the presence of opportunity costs. Let us take a simple example to explain this.

If one has 100 euros now, this could either be consumed or invested in the most profitable alternative (e.g., in a riskless government bond). If the net return on such a bond is $2 \%$, then this means that next year the current 100 euros has grown to 102 euros. This foregone gain of 2 euros in case of not investing in the bond is called the 'opportunity cost' and the present value of 102 euros next year is 100 euros today. Similarly, 100 euros next year equals 98.04 euros now. This can be reflected through discounting (with $2 \%)$.

In the case of health interventions, opportunity costs reflect the opportunity that the resources required for healthcare could also have been invested in some other sector in the economy, which would have yielded a positive rate of return. The opportunity costs are then taken to be the return on the next best investment alternative because this represents the opportunity foregone by investing in the particular healthcare program [5].

Other reasons why we might apply discounting in economic evaluations include pure time preference (impatience), which is a widely observed empirical phenomenon [6], catastrophic risk, and consumption growth (i.e., if one already has more consumption, additional consumption leads to fewer utility gains. This is called 'diminishing marginal utility', implying that people will derive more utility from consumption today than in the future because they are expected to have a higher consumption level in the future as a result of economic growth). These factors are included in the Ramsey equation, which is often applied to compute social discount rates [7-9]. This equation derives the discount rate by considering a pure social time preference rate, the elasticity of marginal utility (i.e., the rate at which marginal utility of consumption declines with the level of consumption) and the growth rate of per capita consumption [10]. Discounting future costs in economic evaluations is currently fairly uncontroversial.

However, a question that emerges from this practice is whether health benefits ought to be discounted as well. If the reasoning holds for money, why should it be valid for health benefits as well? Some may claim that health is a unique commodity, which cannot be traded over time and, hence, it cannot be invested elsewhere at some real rate of return, like most other resources [11]. However, especially at a societal level, the level of decision making in common economic evaluations, one may also argue that healthcare transforms resources into health and because it is possible to trade healthcare resources over time, the same should hold for health [12]. According to this argument, healthcare resources are ultimately transformed into health, implying that if healthcare resources are being discounted, then so should health effects and at the same rate. The tradability of wealth (consumption) and health is a requirement to link the discount rate for health effects to the discount rate for costs. One could say that this tradability is at the heart of economic evaluations. Not spending money now but saving it to next year can yield more health then than the amount can now (ceteris paribus). This also indicates the main logic behind discounting benefits and costs with the same 
discount rate, known as equal discounting. Equal discounting has been the dominant practice for a long time and still is now, with the Ramsey equation or opportunity costs (in the form of riskless returns on government bonds) as the basis of setting discount rates.

The practice of equal discounting of costs and health effects based on these arguments was further strengthened by two influential arguments: the consistency argument of Weinstein and Stason [13] and the postponement paradox of Keeler and Cretin [14]. Weinstein and Stason argued that different discount rates for costs and effects would lead to undesirable inconsistencies over time. They illustrated this with two programs that are identical except for their timing. If one wants these identical programs to receive equal priority in decision making, this can only be accomplished by applying the same discount rate to costs and effects. A crucial assumption in this example, which did not receive much attention for a long time, was that the value of health [e.g., quality-adjusted life-years (QALYs)] would remain stable over time as well. Keeler and Cretin [14] demonstrated an interesting paradox when not using equal discount rates (but rather differential discounting with a lower rate for health than for costs): the cost-effectiveness ratio of a given healthcare intervention will improve with each year it is postponed. Hence, it becomes optimal to postpone the intervention infinitely because the cost effectiveness will keep improving the longer the project is postponed.

These theories and arguments led to a practice in which equal discounting was the dominant strategy, normally using a discount rate of 3-6\%. It must be noted that, despite their influence on discounting practice, both arguments do not appear to be very relevant for actual reimbursement decisions $[15,16]$. First, the consistency argument is only valid if the monetary value of health effects, such as QALYs, is stable over time. In general, this is not to be expected, rather the value of a QALY is expected to grow over time $[8,17]$. More empirical work to directly establish the growth rate of the monetary value of a QALY is encouraged. A growing value of health can be incorporated straightforwardly in a cost-benefit analysis, but is less straightforward in a cost-utility analysis (CUA). Hence, non-differential discounting is harder to defend in a costbenefit analysis than in a CUA, if the growing value is already adequately dealt with. Likewise, alternative options than differential discounting are available in the context of a CUA as well, for instance by adjusting the threshold for the timing of effects. In relation to Weinstein and Stason's argument, it is worth noting that consistency is not a demanding requirement and can be achieved under differential discounting as well [15]. Second, infinite postponing was never observed in practice, and also not in countries recommending differential discounting, such as the UK before 2004 [15] and The Netherlands since 2004 [18, 19]. While these examples do not refute the theoretical relevance of the Keeler-Cretin paradox, they do indicate it has little practical relevance.

Notwithstanding the practical consensus of equal discounting, discounting remained a matter of debate in the literature. Some issues, regarding fairness and regarding the empirical observations about discounting future consumption and health, are highlighted below. More recently, new insights emerged that especially challenged the convention of equal discounting of costs and benefits. These have the potential of also changing discounting practices and guidelines, and already have done so in a number of countries. More insight was also generated on optimal decision rules and the need to specify the decision context $[12,15]$.

\subsection{Recent Developments}

In understanding the recent developments, it must be emphasized that welfare economic evaluations in health should take a specific form, i.e., CUAs in which costs are expressed in a money metric but health benefits in terms of QALYs. This creates the context of a particular reason for applying different discount rates for costs and health effects. The reason for this is fairly straightforward. In a conventional cost-benefit analysis, both costs and effects are expressed in monetary terms. If the value of a particular item is expected to change over time, this can then be directly reflected in this money value. However, in a CUA this is not the case for QALYs. As Gravelle and Smith [17], Brouwer et al. [15], and Klok et al. [7] argue, the monetary value of health (that is, the rate at which we exchange consumption for health, our 'willingness to pay' for health) is expected to grow with increases in income over time. Note that this challenges one of the core assumptions underlying the consistency argument made by Weinstein and Stason [13]. If health becomes more valuable over time, this has to be accounted for in economic evaluations. One possibility to account for the increasing value of health is to use differential discounting, in which the discount rate for health is lowered relative to that of costs to account for its increasing value. ${ }^{1}$ This suggestion led to quite some debate, which highlighted the importance of the decisionmaking context for setting appropriate discount rules and rates.

As Gravelle and Smith [17] indicated, if the consumption value of health grows over time, and decision makers

\footnotetext{
${ }^{1}$ Another method is to adjust the value against which incremental cost-effectiveness ratios are judged (i.e., making it dependent on the timing of the effects) or by inflating quality-adjusted life-year estimates to reflect their increased value.
} 
would be interested in maximizing welfare from their decisions, decision making must account for the growing value of health. (Note that this is true whether the underlying social welfare function is welfarist or extra-welfarist [20].) If reflected through differential discounting, the rate for health should be lowered relative to that of costs, by subtracting the growth rate of the value of health (i.e., $r_{h}=r_{c}-g_{v}$ ) [15]. The National Institute for Health and Care Excellence (NICE) guidelines for discounting (6\% for costs and $1.5 \%$ for effects) were the first to prescribe differential discounting, but rather these were changed back to equal discounting (3.5\% each) [21]. Brouwer et al. [15] questioned this change, also in light of the Dutch guidelines, which were changed in the same period to prescribe differential discounting (4 and $1.5 \%$ for costs and effects, respectively) [19]. Claxton et al. [12] responded and importantly related the change to the decision context of NICE in which, they argued, the value of health was less important than the health opportunity costs of spending. Gravelle et al. [22] showed that the value remains important in case one wishes to maximize welfare (defined in a broad way, so that it could be labeled as welfarist or extrawelfarist [20]). Finally, Claxton et al. [23] bring together the two streams of thought and highlight that if a government wants to specify its discount rates for costs and effects, and, by result, whether to apply differential discounting, it has to answer four crucial questions. The first question is whether their objective is to maximize broader welfare or purely health from a given budget. ${ }^{2}$ The second is whether the healthcare budget is fixed or variable and whether it is set optimally. Third, one should determine whether the marginal productivity of healthcare spending (health opportunity costs) and the consumption value of health are expected to change over time (and at which rate). Fourth, the social time preference rates for consumption and health have to be determined. We now expand these issues further.

First, the decision context matters. Some bodies responsible for allocating healthcare resources, such as NICE in the UK, can be viewed as agents of a socially legitimate higher authority. This agent receives funding from the higher authority with the purpose to attain one or a number of specific objectives, such as improving health [23]. As a result, the healthcare budget can be regarded as fixed. In that case, any new investment necessarily has to come at the expense of investments elsewhere in the

\footnotetext{
${ }^{2}$ Note that the latter approach is sometimes equated with the extrawelfarist approach (e.g. [24]), but wrongfully so. Extra-welfarism allows other sources of value than individually assessed utilities to enter an analysis [20]. The issue of societal welfare vs. health maximization from a given budget is a question of decision context and appropriate perspective. To put it clearly: extra-welfarists can care about costs and benefits outside the healthcare sector.
}

healthcare sector. The opportunity costs will therefore be equal to the expected health foregone owing to the costs of the new investment [23]. For this case, Claxton et al. [23] demonstrate that differential discounting is necessary if the marginal productivity of health spending changes over time; i.e., if less cost-effective treatments are more likely to get funded over time. Box 1 explains this in more detail.

If the policy maker's objective is instead to maximize broader social welfare, the situation gets somewhat more complicated. Claims may then be made about the optimality of exogenous budget constraints, and endogenous budgets can also be taken into account [23]. As shown by Gravelle et al. [22], maximizing social welfare is equivalent to maximizing the present consumption value of health if the healthcare budget is regarded as fixed, and assuming that all costs fall on the healthcare sector. In addition to the marginal productivity of health spending, one now also has to consider the consumption value of health and its expected growth rate. It can again be shown that the appropriate discount rate for health effects is lower than discounting of costs whenever health opportunity costs are growing over time, similarly as in the previous case where health was being maximized (see Box 1). The difference is that both discount rates are lowered by the expected growth rate of consumption value of health [23]. This difference is necessary to account for the fact that future costs are less important than current costs because future costs lead to less health foregone. Note that this growing value of consumption can also be dealt with separately from discounting, for example through increasing monetary thresholds over time reflecting the consumption value of health.

The final possibility is where there is no exogenous budget constraint in the healthcare sector. In that case, the budget is flexible and the resources allocated to healthcare depend on the number of technologies for which the consumption value of health gained exceeds the consumption costs because the marginal costs of accepting new technologies fall on a wider consumption instead of health [23]. If one uses an incremental cost-effectiveness ratio (ICER) and the growth in the consumption value of health is not accounted for elsewhere, the discount rate of health effects will be equal to the social time preference rate for consumption minus the growth rate of the consumption value of health, whereas the discount rate for costs will simply be the social time preference rate.

Recently, it was demonstrated that these issues of perspective are not irrelevant. Paulden et al. [24] criticized the new US Panel on Cost-Effectiveness in Health and Medicine for their recommendations on discounting practice and the proposed height of the discount rates. They highlight inconsistencies in the reasoning of the US Panel, but also indicate that the proposed $3 \%$ discount rate for costs and 
effects is likely to be too high, especially from a healthcare perspective.

\section{Box 1: Discounting in equations \\ Ramsey equation}

In this box, we introduce notation and show the equations typically used to derive discount rates. We denote health effects in each period by $h_{t}$, costs by $c_{t}$, and their discount rates by $r_{h}$ and $r_{c}$, respectively. The Ramsey equation is typically given by:

$D=\delta+\varepsilon_{x} g_{x}$,

where $D$ is the discount rate, $\delta$ is the social time preference rate, $\varepsilon_{x}$ is the elasticity of marginal utility (i.e., the rate at which marginal utility declines in consumption), and $g_{x}$ is the growth rate of per capita consumption $x$ [10]. The Ramsey formula is sometimes amended by a factor $\gamma$ reflecting catastrophic risk, such as in the National Institute of Health and Care Excellence guidelines [66]. The latter reflects the risk of some large-scale disaster and is usually taken to be very small. It follows straightforwardly that the Ramsey equation is then extended to $D=\delta+\varepsilon_{x} g_{x}+\gamma$. (Note that the exact meaning and relevance of pure time preference on a societal level can be debated and it may be claimed it should be set to zero [84].)

Derivation of discount rates for health costs and effects

The foregone health, $\Delta h_{t}$, can be estimated by dividing the costs of the investment, $\Delta c_{t}$, by the marginal cost effectiveness of current spending, $k_{t}: \Delta h_{t}=\Delta c_{t} / k_{t}$. The marginal cost effectiveness of current spending, $k_{t}$, is sometimes called the 'threshold' and from the previous equation it can be shown to be given by $k_{t}=\Delta c_{t} / \Delta h_{t}$. $k_{t}$ is supposed to represent the cost effectiveness of the healthcare being displaced and is measured as a ratio of costs over effects. These health opportunity costs will grow with increasing health budgets and shrink with improvements in marginal productivity [5]. In general, $k$ changes at a growth rate $g_{k}$, giving $k_{t+1}=k_{t}\left(1+g_{k}\right)$. Claxton et al. [23] demonstrate that differential discounting is necessary if the following conditions hold: $r_{c}$ has to be higher than $r_{h}$, where $r_{h}$ is equal to the decision maker's time preference rate, and $r_{c}$ approximately equal to $r_{h}+g_{k}$. The opposite holds if $k_{t}$ decreases over time.

In the full framework, in which welfare maximization is the goal, recognizing potential (suboptimal) fixity of the budget, in addition to $k_{t}$, one also has to consider the consumption value of health, $v_{t}$ (confusingly also sometimes referred to as the 'threshold') and its expected growth rate $g_{v}$. It can be shown that the appropriate discount rate for health effects is equal to $d_{h}=r_{c}-g_{v}$ and the discount rate for costs is $d_{c}=d_{h}+g_{k}$. Hence, the discount rate for effects is given by the social time preference rate for consumption minus the growth rate of $v_{t}$. This reflects the higher valuation of future health in case of $g_{v}>0$. Costs are discounted at the social time preference rate for consumption minus $\mathrm{g}_{\mathrm{v}}$, plus $g_{k}$, which is equal to $d_{h}+g_{k}$ because of the formula for $d_{h}$.

\subsection{Normative or Positive Approach}

In developing discounting guidelines, the relevant authority has to decide on a number of important normative issues. The first is whether to use empirical estimates to set an appropriate discount rate for costs and effects or a normative framework. In the case of the latter, it has been argued to use a zero social time preference rate in order not to discriminate against future generations $[25,26]$. It is clear that such reasoning does not adhere to compelling economic arguments in favor of a non-zero positive discount rate. Others have advocated to have a social rate of time preference lower than the market interest rate because of market distortions and inefficiencies in intergenerational transfers [27, 28].

If instead a descriptive approach is taken, the question is how to obtain discount rates. One method is to rely on empirical estimates of the different components of the Ramsey equation. Of course, this assumes that all components in this equation (including pure time preference or impatience) are considered normatively relevant in the process of setting social discount rates. The elasticity and the growth rate of consumption can in principle be derived from data, but the pure time preference rate of societies and the catastrophic risk parameter are unobservable and have to be determined. Another route is to obtain discount rates from observing how individuals make intertemporal choices (either individually or societally, and the choice between these two is highly relevant and influential). This leads to direct estimates of discount rates. It is needless to say that any of these approaches require different normative motivations and are likely to have a large impact on discounting practices and, ultimately, results from economic evaluations.

Even within a specific framework, normative choices are required, for instance regarding whether to use constant discounting or some other model. The constant discounting model [29] is most often used by social planners. This model is based on discounted utility where costs or utilities in each period are multiplied with the discount factor of this period. The discount factor is given by $1 /(1+D)^{t}$, where $D$ is the discount rate that is applied to each period. Because of compounding, the farther in the future an outcome occurs, the less weight it gets. Therefore, this model is also called the exponential discounting model. This can be justified by pointing to reasons such as time consistency and simplicity [6]. The alternative option is to use hyperbolic discounting, which has been shown to explain individual behavior better $[6,30]$, but also leads to inconsistencies over time. For example, one could prefer Program A over Program B now, but Program B over A in 1 year, even if the options have not changed in any aspect and no new information has arrived. Should a social planner follow these time inconsistent preferences or normatively or paternalistically correct these? Should or can a social discount rate, which arguably should also consider and give fair weight to future generations, somehow be an 
average of individual discount rates anyhow? Again, this shows that these normative choices are highly influential and require explicit attention, also, or perhaps especially, in dealing with health and healthcare.

Allowing the application of differential discounting of costs and health effects also has implications for the practice of economic evaluations. For instance, O'Mahony et al. [31] discuss how the choice of the starting year (to which everything is discounted back) may be influential under differential discounting. This is related to the Keeler and Cretin paradox. The further the starting year is placed before the actual start of the program, the more the ICER will be reduced (if costs are discounted more than effects). Hence, there may be an incentive to expedite the discount year to make a treatment's ICER appear more favorable. This can only be avoided by prescribing a fixed rule for setting the discount year, for instance by making it equal to the year of treatment initiation [31]. A second related practical problem is that ICERs decrease when future cohorts are added to a model with differential discounting $[32,33]$. This is especially relevant for economic evaluations of vaccinations with indirect effects stretching far into the future. If cost-effectiveness analyses with different numbers of future cohorts have to be analyzed, their comparability will be compromised [31]. Consequently, O'Mahony et al. [31] recommend countries with a differential discounting policy to also report outcomes for equal discounting at rates of 3 and $5 \%$, to clearly define the simulated cohorts (including their ages at the onset of the intervention), and to always report the discount year and intervention year. This avoids strategic behavior in setting the discount year, initiation year, and number of cohorts. The justification of the choice of the relevant time horizon is therefore important. However, we should note that the problem of comparability of multiple cohorts has at present not yet been fully resolved. ${ }^{3}$

In addition, care should be taken to avoid that differential discounting is applied in selective cases, as has been recommended by NICE for "treatment effects are both substantial in restoring health and sustained over a very long period (normally at least 30 years)" [34]. As shown by O'Mahony and Paulden [33], this may lead to inconsistencies and strategic behavior to ensure more favorable cost-effectiveness ratios for specific drugs or treatments. Any differentiation in discounting practices should be clearly normatively justified, relevant to the policy question the economic evaluation should address, and practically operationalized.

\footnotetext{
${ }^{3}$ We thank an anonymous referee for this observation.
}

\subsection{Sources of Discount Rates}

In attempts to come to empirical estimates of discount rates, two broad streams can be distinguished. The first stream attempts to find empirical estimates of the arguments in normative theory, such as the elements included in the Ramsey equation or those observing policy tradeoffs between current and future health. The empirical basis for $r_{c}$ is currently often linked to the cost of borrowing, which can explain the lower discount rates now than in older guidelines, when both nominal and real government borrowing costs were considerably higher. Arguably, such research is still relatively scarce, also in the field of health economics and, therefore, encouraged. Accurate estimates of the relevant elements in the decision rule, including for the consumption value of health $(v)$, the marginal productivity of current spending $(k)$, and how these evolve over time, remain crucial.

The second stream involves measuring time preference in individuals to inform social discount rates. The underlying notion is that social discount rates could, or perhaps even should, be somehow based on individual time preferences. (Note that understanding individual time preference to understand individual behavior is important in itself.) Such an approach may be considered problematic both for normative reasons (can/should social time preference be based on individual time preference?) and practical reasons because individual time preference for health can be relatively high, often involve time inconsistent hyperbolic discount functions [30], and its application in social decisions may thus lead to undesirable outcomes.

Some have suggested using 'two-stage discounting', where the stream of health benefits in an individual is discounted using some appropriate individual rate/function of time preference back to the start of the stream for that individual, but differences in timing of individuals' net present values are discounted using a social discount rate to the start of the intervention [35]. This thus applies individual rates to individual streams of health and the social discount rate to adjust for their timing. The social discount rate can then be different (often lower) than the individual discount rate [35]. Such a procedure does justice to the fact that individual time preferences may be considered relevant for calculating the net present value of an individual health stream. At the same time, it acknowledges the relevance of social time preference when comparing and aggregating across individuals. However, not only might one argue that in social decision making the social value attached to future health may be more important than the involved individual's value, the procedure moreover does not solve other issues. Most notably, it also combines the need for sound empirical estimates for individual and social time preferences. 


\subsection{Equity}

As with other choices, besides issues of efficiency, issues of equity play an important role in the context of discounting, especially when it comes to health and healthcare. Choices for discount procedures and rates have equity implications as well as efficiency implications. For instance, if the time horizon of an economic evaluation is (very) long, then the compounding nature of constant discounting has the effect of leaving a close to zero weight for future generations, which has been argued to be an undesirable and unfair feature of constant discounting $[2,25,36]$. This is especially relevant in environmental economics, where the time horizon of investments tends to be very long, but it is also important in health economics. For example, interventions against infectious diseases that involve herd protection may span a multitude of cohorts [2]. One might argue that there still is a need to further explore the equity-efficiency trade-off in the context of discounting in the area of healthcare. Sometimes, a discount rate that decreases over time is proposed, as perhaps a pragmatic approach, in order to prevent the very distant future from receiving virtually no weight at all [2]. This resembles hyperbolic discounting in the sense that lower discount rates are applied to more distant time periods. While this diminishes the problem of a low weight to future generations, the normative underpinning of the procedure and applied rates remains important. One possibility could be that over longer time horizons, the uncertainty about the estimated parameters (e.g., in a Ramsey equation) becomes larger, which could be reflected in lowering the rate [37]. However, one should be aware that not all equity considerations can best be reflected in discounting procedures, especially regarding non-renewable resources. In general, explicit consideration of equity issues seems warranted.

Another example of equity implications of different discount rules is that under differential discounting, with effects discounted at a lower rate than costs, programs that run longer may be advantaged over those that run shorter, ceteris paribus, given that ICERs improve over time. Such procedures have equity implications that are important to consider. If the justification for differential discounting is found in the growing value of health, this may imply more weight to generations that are richer and, hence, already have more possibilities to produce health.

In any circumstance, it needs to be clear that any choice regarding the mode of discounting as well as specific discount rates will lead to issues of efficiency as well as distributional consequences. The equity implications of different discounting rules (within and across generations) deserve more attention.

\subsection{Double Discounting}

Another issue that has not received sufficient attention in the literature is that of double discounting. As noted before, health effects are typically expressed in terms of QALYs. The QALY weights attached to specific health states are normally derived through elicitation techniques that have some time component, which respondents need to consider. For instance, the popular time trade-off (TTO) method typically asks respondents to trade-off a longer period of time (often 10 years) in an imperfect health state to a shorter period in perfect health. It has been shown that respondents, as would be expected, have a time preference for health [38]. In a TTO exercise, this discounting causes a downward bias on the utilities of health states elicited by means of a TTO task [39]; people give up relatively many years because they do not attach full weight to future years. This implies that the utilities derived are already discounted in a way that was relevant from an individual perspective in the elicitation exercise (which may be different from what is appropriate from a social perspective and relevant in the context of an economic evaluation, e.g., in terms of a time horizon). Currently, these utilities that are 'distorted' by individual discounting are used, uncorrected, in economic evaluations. In those evaluations, they are then 'again' discounted using some standard discount rate. It is clear that this results in double discounting of QALYs [40]. Procedures are available that can be used to correct TTO values for discounting [38, 41, 42]. To date, this correction seems not to be used in practice.

\section{Current Practice and National Guidelines}

\subsection{National Guidance}

National guidelines for discounting in health economic evaluations differ between countries and over time. Table 1 provides an overview of the current guidelines of countries that provide a recommendation for discount rates. ${ }^{4}$ The table shows that most guidelines recommend discounting costs and effects at the same rate, without clear justifications. However, there is considerable variation between countries, with discount rates varying between 0 and 5\%. The guidelines are also subject to change. For example, the UK used to have discount rates of $6 \%$ for costs and $1.5 \%$ for effects until 2004, but now has 3.5\% for both costs and effects [43]. Four national guidelines currently recommend differential discounting, those in Belgium, The Netherlands, Poland, and

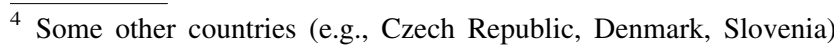
only prescribe to discount future outcomes, but give no recommendations about the discount rate.
} 
Table 1 National guidelines on discounting in health economic evaluations

\begin{tabular}{|c|c|c|c|}
\hline Country & Costs & Effects & Justification \\
\hline Australia [44] & $5 \%$ & $5 \%$ & - \\
\hline Austria [45] & $3 \%$ (sens. $0,5,10 \%)$ & $3 \%$ (sens. $0,5,10 \%)$ & - \\
\hline Belgium [46] & $3 \%$ (sens. $0,5 \%$ ) & $1.5 \%$ (sens. $0,3,5 \%$ ) & $\begin{array}{l}\text { Differential discounting: avoid a too strong penalization of } \\
\text { interventions that generate most of their benefits in the } \\
\text { future (e.g., screening and vaccination programs) } \\
\text { Costs: allow the comparison with previous economic } \\
\text { evaluations } \\
\text { Prefers consistency in the discount rate above a fluctuating } \\
\text { one } \\
\text { Effects: awaiting further evidence, and to remain consistent } \\
\text { with previous guidelines }\end{array}$ \\
\hline Canada [47] & $1.5 \%$ (sens. $0,3 \%$ ) & $1.5 \%$ (sens. $0,3 \%$ ) & Long-term cost of borrowing for Canadian provinces \\
\hline Croatia $[48]$ & $3 \%$ (sens. $0,5 \%$ ) & $3 \%$ (sens. $0,5 \%$ ) & $\begin{array}{l}\text { Based on the calculated mean of the base rate for four } \\
\text { quarters within a respective year, over the last } 3 \text { years } \\
\text { (reflecting the Croatian trend in the base rate and discount } \\
\text { rate over the last } 3 \text { years) }\end{array}$ \\
\hline $\begin{array}{l}\text { Estonia, } \\
\text { Latvia, } \\
\text { Lithuania } \\
\text { [49] }\end{array}$ & $5 \%$ & $5 \%$ & - \\
\hline Finland [50] & $3 \%$ & $3 \%$ & - \\
\hline France $[51]$ & $\begin{array}{l}4 \%(<30 \text { years, } \\
\text { reduction of up to } \\
2 \% \text { thereafter })\end{array}$ & $\begin{array}{l}4 \%(<30 \text { years, reduction of up to } 2 \% \\
\text { thereafter })\end{array}$ & For the purpose of international comparisons \\
\hline Germany [52] & $3 \%$ (sens. $0,5 \%$ ) & $3 \%$ (sens. $0,5 \%)$ & $\begin{array}{l}\text { Based on the present international long-term equity market } \\
\text { costs }\end{array}$ \\
\hline Hungary [53] & $3.7 \%$ (sens. $2-5 \%$ ) & $3.7 \%$ (sens. $0-5 \%$ ) & Based on the Ramsey equation with domestic empirical data \\
\hline Ireland [54] & $5 \%$ (sens. $0-6 \%$ ) & $5 \%$ (sens. $0-6 \%$ ) & Based on guidelines from the Department of Finance \\
\hline Italy [55] & $3 \%$ (sens. $0,8 \%$ ) & $3 \%$ (sens. $0,8 \%$ ) & $\begin{array}{l}\text { Same discount rate on the basis of theoretical foundations, } \\
3 \% \text { because this is in line with the cost opportunity and } \\
\text { more appropriate for comparing to the different existing } \\
\text { studies }\end{array}$ \\
\hline $\begin{array}{l}\text { The } \\
\text { Netherlands } \\
{[56]}\end{array}$ & $4 \%$ & $1.5 \%$ & $\begin{array}{l}\text { Costs: based on current returns on obligations and the } \\
\text { literature } \\
\text { Effects: based on the literature, and on the fact that the value } \\
\text { of health is increasing }\end{array}$ \\
\hline $\begin{array}{l}\text { New Zealand } \\
\text { [57] }\end{array}$ & $\begin{array}{l}3.5 \% \text { (sens. } 0 \text { and } \\
5 \% \text { ) }\end{array}$ & $3.5 \%$ (sens. 0 and $5 \%)$ & $\begin{array}{l}\text { Social rate of time preference is the most relevant approach, } \\
\text { as it reflects society preferences. This requires the use of } \\
\text { the 5-y, average, real risk-free, long-term government bond } \\
\text { rate } \\
\text { Same rate because of Weinstein and Stason's [13] and Keeler } \\
\text { and Cretin's [14] arguments, and because no or lower } \\
\text { discounting of effects would be unfair to current patients } \\
\text { vs. future patients }\end{array}$ \\
\hline Norway [58] & $4 \%$ & $4 \%$ & $\begin{array}{l}\text { Recommended by the Ministry of Finance for public projects } \\
\text { with a moderate systematic risk, currently at } 4 \% \text { per year }\end{array}$ \\
\hline Poland [59] & $5 \%$ (sens. $0 \%$ ) & $3.5 \%$ (sens. $0,5 \%$ ) & - \\
\hline Portugal [60] & $5 \%$ & $5 \%$ & $\begin{array}{l}\text { Based on a real long-term market interest rate and because } \\
\text { most other countries use it. Open for differential } \\
\text { discounting, if justified }\end{array}$ \\
\hline Russia [61] & $5 \%$ & $0 \%$ & - \\
\hline $\begin{array}{l}\text { Slovak } \\
\text { Republic } \\
\text { [62] }\end{array}$ & $5 \%$ & $5 \%$ & - \\
\hline
\end{tabular}


Table 1 continued

\begin{tabular}{|c|c|c|c|}
\hline Country & Costs & Effects & Justification \\
\hline Spain $[63,64]$ & $\begin{array}{l}\text { CatSalut 3\% (sens. } \\
5 \% \text { ) } \\
\text { OSTEBA 5\% (sens. } \\
0 \% \text { ) }\end{array}$ & $\begin{array}{l}\text { CatSalut 3\% (sens. 0\%, 5\%) } \\
\text { OSTEBA 5\% (sens. 0\%, 3\%) }\end{array}$ & - \\
\hline Sweden [65] & $3 \%$ (sens. $0 \%, 5 \%$ ) & $3 \%$ (sens. $0 \%, 5 \%$ ) & - \\
\hline UK [66] & $3.5 \%$ (sens. $1.5 \%)$ & $\begin{array}{l}3.5 \% \text { (sens. } 1.5 \% \text { ) } \\
1.5 \% \text { in case of therapies with long- } \\
\text { term health benefits and for public } \\
\text { health interventions }\end{array}$ & $\begin{array}{l}\text { Catastrophic risk rate of } 1 \% \\
\text { Expected income growth rate of } 2 \% \\
\text { Pure time preference rate of } 0.5 \%\end{array}$ \\
\hline
\end{tabular}

sens. discount rates that have to be included in a sensitivity analysis

Russia. The table also shows that $5 \%$ is the most common discount rate, followed by $3 \%$. These rates are high, and we argue below why lower discount rates currently may be considered to be more appropriate.

Most countries explicitly recommend sensitivity analyses with specified alternative discount rates (including no discounting) that accompany the base-case analysis to examine whether the results of the economic evaluation are affected by the choice of the discount rate and procedure. Furthermore, Spain and Sweden, which suggest the same discount rate for costs and effects in the base-case analysis, recommend the use of differential discounting in sensitivity analyses. The UK recommends a rate of $3.5 \%$ for costs and effects, which comprises a catastrophic risk rate of $1 \%$, an expected income growth rate of $2 \%$, and a pure time preference rate of $0.5 \%$ [23]. This discount rate is progressively lowered toward $1 \%$ for costs and effects occurring more than 30 years ahead [5]. Another peculiarity is the special case made by NICE for therapies with long-term benefits, where differential discounting is recommended with a lower discount rate for health effects of $1.5 \%$. Although this exception may have some merits, this decision has been heavily criticized for being ambiguous, inconsistent, and unjustified [33]. It is unclear to what extent this declining discounting rule is applied in practice.

The guidelines also give some motivation for their discounting requirements. For instance, the Pharmaceutical Management Agency of New Zealand [57] assumes the threshold stays constant over time and uses the consistency argument and Keeler-Cretin paradox to advocate discounting costs and effects at the same rate. In addition, they argue that the discount rate should represent the social rate of time preference and that this can be determined from the long-term government bond rate. They require the inclusion of discount rates of 0 and $5 \%$ in sensitivity analyses to compute the impact of discounting $(0 \%)$ and to enable comparison with analyses in other countries (5\%). The Canadian Agency for Drugs and Technologies in Health also argues for the use of a social discount rate and therefore recently lowered its prescribed discount rate from 5 to $1.5 \%$ for both costs and effects, reflecting recent empirical evidence on the long-term cost of borrowing for Canadian provinces, adjusted for inflation. This agency's guidelines suggest to explore the impact of non-constant discounting only in non-reference case analyses [47]. In general, the justification provided for applied discount rates and rules appears to be limited, also in relation to the wider guidelines and decision-making context.

\subsection{Current Practice}

A systematic review showed that discounting practice in economic evaluations carried out between 1992 and 1998 did not always comply with national guidelines [67]. Ninety percent of the reviewed studies used the same discount rate for costs and effects, but these included many studies (28\%) that did not discount future outcomes at all. Among studies using a positive discount rate, $5 \%$ for both costs and effects was the most prominent. Hence, as for other subjects, it is possible that the practice of discounting in published studies deviates from guidelines. Differences in discounting rules and rates in the guidelines and practice may not only misinform decision makers, but also hamper the comparability of study results.

\section{Discussion of Different Approaches to Discounting}

\subsection{Height of Discount Rates}

Claxton et al. [23] argue that it is very unlikely that the discount rate will be equal to the social time preference rate for consumption, even when the marginal productivity of health spending will remain constant. This is because it is very plausible that the consumption value of health will 
grow over time, justifying a lower discount rate than the social time preference rate for both health and costs. Several studies claim that this discount rate is lower for the UK than the currently prescribed $3.5 \%[5,15,23,68]$. The countries shown in Table 1 are not expected to differ enormously with regard to the components of the discount rates as described in Sect. 2, implying that their prescribed discount rates are also likely to be too high; in particular, the countries where $5 \%$ discounting of costs and effects is currently recommended. For example, Paulden and Claxton [68] advocate a discount rate of 1 or $1.5 \%$ for NICE if the health opportunity costs $(k)$ are not expected to grow over relevant time horizons. Likewise, the currently prescribed discount rate of $4 \%$ for costs in The Netherlands may also be considered to be too high. Given the assumption of an optimal budget, this would imply a growth rate of both the health opportunity costs $(k)$ and the consumption value of health $(v)$ of approximately $4-$ $1.5 \%=2.5 \%$, which, also in light of economic developments over the last years, appears to be quite high. Note that this remark is not a dismissal of the principle of differential discounting, but an observation regarding its current operationalization. (An alternative could be to use a $3 \%$ for costs and $1.5 \%$ for effects, implying a lower discount rate for costs and a lower growth rate of the value of health of $1.5 \%$.) This stresses the need for more empirical research. Moreover, in general, a trade-off needs to be made between stability and comparability of discount rates over time (which enhances comparability of the results of economic evaluations and avoids continuous changes in methods) and a reflection of realistic estimates of societal discount rates needs to be performed. More research is required to provide a solid justification of the growth rates and the assumption of an optimal budget (growth).

Because the previous parts of this article showed that time preferences are an important component of the discount rate, it is necessary to elicit these empirically with robust methods. Much work is required, which may involve estimates directly relevant for social time preference and estimates at an individual level. In relation to the latter, several attempts have been made in the literature to measure health-related time preferences, and to compare them to time preferences for money. These studies have used a wide variety of methods and samples, and showed a lot of heterogeneity, with average discount rates varying between 0 and $45 \%$ [69-80]. As mentioned above, given that experimental elicitations of time preference for health outcomes tend to provide much variability and high average discount rates (partly because the variety of different methods used), one may question whether such data in individual preferences can be meaningfully used in informing societal decisions, which also have a normative component and need to consider future generations [15].
The alternative approach, estimating the elements relevant to establish a social time preference rate, may involve an estimation of the Ramsey equation or a time preference derivation from health budget allocations in subsequent periods, as suggested by Paulden and Claxton [68]. Recently, Paulden et al. [81] reported on estimates for Canada, informing new Canadian guidelines.

\subsection{Constant or Hyperbolic Discounting}

Considering estimates of individual time preference, there is also considerable experimental evidence rejecting constant discounting of health effects [30, 82], although some studies report a better fit of constant discounting than of hyperbolic discounting [69, 83]. While the descriptive validity of hyperbolic discounting in elicitations of time preferences for health among the general public is generally found to be higher than that of constant discounting, almost all guidelines prescribe the use of constant discount rates. This is likely to reflect a difference between individual and social discount rates. Interestingly, the French and UK's guidelines do recommend declining discount rates for projects that span time horizons of more than 30 years. Although the reason for this declining rate may be different at the social rather than individual level (e.g., increasing uncertainty regarding the relevant parameters in the long term), it may be worthwhile to investigate its underpinning and practical operationalization further.

\section{Research Agenda}

In this section, we emphasize a number of topics that require particular attention in future research on appropriate discounting policies in health economic evaluations. First, it is clear that discounting rules should be consistent with the decision context and framework adopted for the full economic evaluation. The explication (and formalization) of the decision framework and discounting rules provides direction for future research, both in a normative and empirical sense. In that context, wider debates, for instance on how to express the outcomes of an economic evaluation, e.g., in terms of net effects on health or consumption (costs), will help to more clearly address the relevant issues regarding discounting. It can also help in separating time preference from changes in consumption, the consumption value of health $(v)$ or opportunity costs of healthcare spending $(k)$ over time. From the overview of national guidelines, it becomes clear that the underpinning of discounting rules, as well as their relation to the broader guidelines, are not well developed.

Second, solid estimations of the health opportunity costs, $k$, the consumption value of health, $v$, and their evolution over time (i.e., their growth rates) are lacking, 
but essential to properly assess the health and welfare effects of healthcare interventions with long-term consequences. More empirical work is needed to obtain these estimates, especially given their pivotal role in determining discount rates. At the same time, we should strive for stability and comparability over time, which can be achieved by altering the prescribed discount rates occasionally instead of frequently.

Third, more empirical work is needed on (implied) policy makers' discount rates because most empirical estimates have been obtained with students or the general public. We have discussed that these estimates differ widely between and within studies, and, hence, careful experimental studies eliciting time preferences of policy makers should also be undertaken, next to studies deriving their social time preference from observed behaviors. In terms of individual and social rates of time preference, forms of two-stage discounting could be investigated further, both empirically as well as normatively.

Fourth, more research is required on equity considerations and discounting rules, which are particularly relevant for interventions with long-lasting consequences, potentially affecting multiple generations. In this article, we highlighted that discounting policies can be modified to give more weight to future generations, but such policies require better normative and empirical underpinning.

Fifth, it is important to obtain improved correction mechanisms for the effects of double discounting $[1,38,40]$, and to start implementing these mechanisms when discounting QALYs in economic evaluations. Otherwise, effects will be underestimated, especially in economic evaluations of interventions with long-term consequences, such as prevention programs.

Sixth, if a country's national guidelines prescribe differential discounting, one has to be aware of the possibility of strategic behavior in the choice of the analytical horizon [31]. We therefore advocate future studies to formulate rules to determine these horizons in the case of differential discounting.

Finally, reporting of economic evaluations remains an important issue. Besides the above-mentioned manner in which end results are expressed, clear reporting on how discounting was executed and why remains pivotal, also in comparing (results of) studies.

\section{Conclusion}

In this study, we have summarized the theoretical foundations of discounting in health economic evaluations and presented the most recent national guidelines for discounting practice. We also discussed the major challenges in setting discounting policy, including the need for explicit discounting rules, the use of equal vs. differential discounting, the role of intergenerational equity, and how to deal with double discounting, multiple cohorts, and long-term time horizons. In addition, we stressed the importance of obtaining more accurate empirical measurements of the growth rates of the consumption value of health and marginal productivity of the healthcare sector. Our review of national guidelines made clear that equal discounting of costs and effects is the dominant practice. This is typically done without any justification or based on theoretical grounds without practical relevance or evidence. We argued to be more cautious in this practice, in particular when the value of health (and the marginal productivity of the healthcare sector) is expected to change over time. Furthermore, the level of the currently used discount rates seems relatively high in many countries in light of current economic developments. The trade-off between stability of methods and discount rates, their applicability over longer time horizons, and their empirical basis need more explicit attention. Finally, we put forward a research agenda with topics that deserve special attention in the search for improved discounting guidelines.

Author contributions WB had the initial idea of this study. AA reviewed the national guidelines and wrote the first draft of the paper. WB commented on this draft and added several parts. KC commented and elaborated on the final draft.

\section{Compliance with Ethical Standards}

Funding No sources of funding were received for the preparation of this article.

Conflict of interest Arthur E. Attema, Werner B.F. Brouwer, and Karl Claxton have no conflicts of interest directly relevant to the content of this article.

Open Access This article is distributed under the terms of the Creative Commons Attribution-NonCommercial 4.0 International License (http://creativecommons.org/licenses/by-nc/4.0/), which permits any noncommercial use, distribution, and reproduction in any medium, provided you give appropriate credit to the original author(s) and the source, provide a link to the Creative Commons license, and indicate if changes were made.

\section{References}

1. Attema AE, Brouwer WBF. The value of correcting values: influence and importance of correcting TTO scores for time preference. Value Health. 2010;13:879-84.

2. Jit M, Mibei W. Discounting in the evaluation of the cost-effectiveness of a vaccination programme: a critical review. Vaccine. 2015;33:3788-94.

3. Westra TA, Parouty M, Brouwer WB, Beutels PH, Rogoza RM, Rozenbaum $\mathrm{MH}$, et al. On discounting of health gains from human papillomavirus vaccination: effects of different approaches. Value Health. 2012;15:562-7. 
4. Drummond MF, Sculpher MJ, Claxton K, Stoddart GL, Torrance GW. Methods for the economic evaluation of health care programmes. Oxford: Oxford University Press; 2015.

5. Paulden M. Time preference and discounting. In: Culyer AJ, editor. Encyclopedia of health economics. Newnes: Elsevier; 2014. p. 395-403.

6. Frederick S, Loewenstein G, O'Donoghue T. Time discounting and time preference: a critical review. $J$ Econ Lit. 2002;40:351-401.

7. Klok RM, Brouwer WBF, Annemans LJP, Bos JM, Postma MJ. Towards a healthier discount procedure. Expert Rev Pharmacoecon Outcomes Res. 2005;5:59-63.

8. van Hout BA. Discounting costs and effects: a reconsideration. Health Econ. 1998;7(7):581-94.

9. Schad M, John J. Towards a social discount rate for the economic evaluation of health technologies in Germany: an exploratory analysis. Eur J Heal Econ. 2012;13:127-44.

10. Ramsey FP. A mathematical theory of saving. Econ J. 1928;38:543-59.

11. Chapman GB. Your money or your health: time preference and trading money for health. Med Decis Mak. 2002;22:410-6.

12. Claxton K, Sculpher M, Culyer A, McCabe C, Briggs A, Akehurst $\mathrm{R}$, et al. Discounting and cost-effectiveness in NICE: stepping back to sort out a confusion. Health Econ. 2006;15:1-4.

13. Weinstein MC, Stason WB. Foundations of cost-effectiveness analysis for health and medical practices. $\mathrm{N}$ Engl J Med. 1977;296:716-21.

14. Keeler EB, Cretin S. Discounting of life-saving and other nonmonetary effects. Manag Sci. 1983;29:300-6.

15. Brouwer WB, Niessen LW, Postma MJ, Rutten FF. Need for differential discounting of costs and health effects in cost effectiveness analyses. BMJ. 2005;331:446-8.

16. Cairns J. Discounting and health benefits: another perspective. Health Econ. 1992;1:76-9.

17. Gravelle H, Smith D. Discounting for health effects in costbenefit and cost-effectiveness analysis. Health Econ. 2001;10(7):587-99.

18. College voor Zorgverzekeringen. Evaluatie Farmaco-economie: Procedure en Inhoud; Stand van zaken na 10 dossiers. Diemen: College voor Zorgverzekeringen (CVZ); 2004.

19. College voor Zorgverzekeringen. Guidelines for pharmacoeconomic research, updated version; 2006.

20. Brouwer WBF, Culyer AJ, van Exel NJA, Rutten FFH. Welfarism vs. extra-welfarism. J Health Econ. 2008;27:325-38.

21. National Institute for Health and Care Excellence. Guide to the methods of technology appraisal. London: National Institute for Health and Care Excellence; 2004.

22. Gravelle H, Brouwer W, Niessen L, Postma M, Rutten F. Discounting in economic evaluations: stepping forward towards optimal decision rules. Health Econ. 2007;16(3):307-17.

23. Claxton K, Paulden M, Gravelle H, Brouwer W, Culyer AJ. Discounting and decision making in the economic evaluation of health care technologies. Health Econ. 2011;20:2-15.

24. Paulden M, O'Mahony JF, McCabe C. Discounting the recommendations of the second panel on cost-effectiveness in health and medicine. Pharmacoeconomics. 2017;35:5-13.

25. Tinghög G. Discounting, preferences, and paternalism in costeffectiveness analysis. Health Care Anal. 2012;20:297-318.

26. Schelling TC. Intergenerational discounting. Energy Policy. 1995;23:395-401.

27. US Environmental Protection Agency. Guidelines for preparing economic analyses. Washington, DC: US Environmental Protection Agency; 2010.

28. Arrow KJ, Cline WR, Maler K-G, Munasinghe L, Squitieri R, Stiglitz JE. Intertemporal equity, discounting, and economic efficiency. In: Lee H, Haites EF, editors. Bruce JP. Cambridge: Cambridge University Press; 1996. p. 125-44.

29. Samuelson P. A note on the measurement of utility. Rev Econ Stud. 1937;4:155-61.

30. Attema AE. Developments in time preference and their implications for medical decision making. J Oper Res Soc. 2012;63:1388-99.

31. O'Mahony JF, Newall AT, van Rosmalen J. Dealing with time in health economic evaluation: methodological issues and recommendations for practice. Pharmacoeconomics. 2015;33:1255-68.

32. O'Mahony J, De Kok I, Van Rosmalen J, Habbema JDF, Brouwer W, Van Ballegooijen M. Practical implications of differential discounting of costs and health effects in cost-effectiveness analysis. Value Health. 2011;14(4):1174-5.

33. O'Mahony JF, Paulden M. NICE's selective application of differential discounting: ambiguous, inconsistent, and unjustified. Value Health. 2014;17:493-6.

34. National Institute for Health and Care Excellence. Discounting of health benefits in special circumstances. London: National Institute for Health and Care Excellence; 2011.

35. Lipscomb J. Time preference for health in cost-effectiveness analysis. Med Care. 1989;27(3 Suppl.):S233-53.

36. Portney PR, Weyant JP. Discounting and intergenerational equity. New York: Routledge; 1999.

37. Claxton K. Accounting for the timing of costs and benefits in the evaluation of health projects relevant to LMICs. 2017. https:// cdn2.sph.harvard.edu/wp-content/uploads/sites/94/2017/09/ Claxton-discounting-2017.10.28.pdf. Accessed 12 May 2018.

38. Attema AE, Brouwer WBF. The correction of TTO-scores for utility curvature using a risk-free utility elicitation method. J Health Econ. 2009;28:234-43.

39. Bleichrodt H. A new explanation for the difference between time trade-off utilities and standard gamble utilities. Health Econ. 2002;456:447-56.

40. MacKeigan LD, Gafni A, O'Brien BJ. Double discounting of QALYs. Health Econ. 2003;12:165-9.

41. Attema AE, Brouwer WBF. Can we fix it? Yes we can! But what? A new test of procedural invariance in TTO-measurement. Health Econ. 2008;17:877-85.

42. Lipman SA, Attema AE, Brouwer WBF. QALYs without bias? Non-parametric correction of time trade-off and standard gamble utilities based on prospect theory. Working paper; Erasmus University Rotterdam; 2017.

43. National Institute for Health and Care Excellence. Technical guidance for manufacturers and sponsors on making submissions for a technology appraisal. London: National Institute for Health and Care Excellence; 2001.

44. Pharmaceutical Benefits Advisory Committee. Guidelines for preparing a submission to the Pharmaceutical Benefits Advisory Committee (version 5.0). Australian Government Department of Health; 2016. https://pbac.pbs.gov.au/. Accessed 12 May 2018.

45. Bundesinstitut für Qualität im Gesundheitswesen (BIQG) und Gesundheit Österreich $\mathrm{GmbH}$. Methodenhandbuch für HTA version 1.2012. Wien; 2012. https://hta.lbg.ac.at/uploads/ tableTool/UllCmsPage/gallery/Methodenhandbuch.pdf. Accessed 12 May 2018.

46. Irina C, Mattias N, Stefaan VDS, Nancy T. Belgian guidelines for economic evaluations and budget impact analyses: second edition. KCE reports. Brussels: Belgian Health Care Knowledge Centre; 2012. https://kce.fgov.be/sites/default/files/page_ documents/KCE_183C_economic_evaluations_second_edition. pdf. Accessed 12 May 2018.

47. CADTH. Guidelines for the economic evaluation of health technologies, 4th edn. Canada; 2006. https://www.cadth.ca/sites/ default/files/pdf/guidelines_for_the_economic_evaluation_of health_technologies_canada_4th_ed.pdf. Accessed 12 May 2018. 
48. Agency for Quality and Accreditation in Health Care. The Croatian guideline for health technology assessment process and reporting, 1st ed. Zagreb: Department for Development, Research and Health Technology Assessment; 2011.

49. Experts from health authorities of the Baltic Countries. Baltic guideline for economic evaluation of pharmaceuticals (pharmacoeconomic analysis). 2002. https://www.ispor.org/peguidelines/ source/Baltic-PE-guideline.pdf. Accessed 12 May 2018.

50. Ministry of Social Affairs and Health, Pharmaceuticals Pricing Board. Guidelines for preparing a health economic evaluation, Annex to the Decree of the Ministry of Social Affairs and Health on applications and price notifications made to the Pharmaceuticals Pricing Board (201/2009). Finland; 2011. http://www.hila. fi/c/document_library/get_file?folderId=1133981\&name=DLFE9844.pdf. Accessed 12 May 2018.

51. Haute Autorité de Santé. Choices in methods for economic evaluation. Saint-Denis La Plaine: Department of Economics and Public Health Assessment, Haute Autorité de Santé; 2012. https:// www.has-sante.fr/portail/upload/docs/application/pdf/2012-10/ choices_in_methods_for_economic_evaluation.pdf. Accessed 12 May 2018.

52. German National Institute for Quality and Efficiency in Health. General methods for the assessment of the relation of benefits to costs (version 1.0 dated 19/11/2009). Cologne; 2009. https:// www.iqwig.de/.../General_Methods_for_the_Assessment_of_ the_Relation_of_Benefits_to_Costs.pdf. Accessed 12 May 2018.

53. Szende Á, Mogyorosy Z, Muszbek N, Nagy J, Pallos G, Dözsa C. Methodological guidelines for conducting economic evaluation of healthcare interventions in Hungary: a Hungarian proposal for methodology standards. Eur J Health Econ. 2002;3:196-206.

54. Health Information and Quality Authority. Guidelines for the economic evaluation of health technologies in Ireland. Cork: Health Information and Quality Authority; 2014. https://www. hiqa.ie/system/files/Revised_Economic_Guidelines_posted_ 100714.pdf. Accessed 12 May 2018.

55. Capri S, Ceci A, Terranova L, Merlo F, Mantovani L. Guidelines for economic evaluations in Italy: recommendations from the Italian group of pharmacoeconomic studies. Drug Inf J. 2001;35:189-201.

56. National Health Care Institute. Guideline for economic evaluations in healthcare. Diemen; 2016. https://english. zorginstituutnederland.nl/publications/reports/2016/06/16/ guideline-for-economic-evaluations-in-healthcare. Accessed 12 May 2018.

57. Pharmaceutical Management Agency of New Zealand. Prescription for pharmacoeconomic analysis: methods for cost-utility analysis. 2015. https://www.pharmac.govt.nz/assets/pfpa-final. pdf. Accessed 12 May 2018.

58. Norwegian Medicines Agency. Guidelines on how to conduct pharmacoeconomic analyses. Oslo: Norwegian Medicines Agency; 2012. https://legemiddelverket.no/Documents/English/ Priceandreimbursement/Applicationforreimbursement/ Pharmacoeconomicguidelines-Norway.pdf. Accessed 12 May 2018.

59. Agency for Health Technology Assessment. Guidelines for conducting health technology assessment (part 4 and 5). Warsaw; 2009. https://www.ispor.org/PEguidelines/source/Poland Guidelines-for-Conducting-HTA_English-Version.pdf. Accessed 12 May 2018.

60. Alves da Silva E, Gouveia Pinto C, Sampaio C, Pereira JA, Drummond M, Trindade R. Guidelines for economic drug evaluation studies. Lisboa: INFARMED; 1998. http://www.infarmed. pt/documents/281/1432055/PCAEC04_vering.pdf. Accessed 12 May 2018.

61. ISPOR Russian HTA Chapter. Protocol on the procedure for clinical and economic evaluation of drugs which are submitted for inclusion into reimbursed drug lists. Moscow: Russian State Medical University; 2010. https://www.ispor.org/PEguidelines/ source/Russia_PE_Recommendations_english_fnal_13_03.pdf. Accessed 12 May 2018.

62. Ministry of Health of the Slovak Republic. Guidelines for economic evaluation of health care interventions. Slovak Republic: Ministry of Health of the Slovak Republic; 2011. http://www. zakonypreludi.sk/zz/2011-422. Accessed 12 May 2018.

63. CatSalut. Guidance for economic evaluation and budget impact analysis for pharmaceuticals in Catalonia. Spain; 2014. http:// catsalut.gencat.cat/web/.content/minisite/catsalut/proveidors_ professionals/medicaments_farmacia/farmaeconomica/caeip/ documents/gaeip_publica_castellano_octubre2014_catsalut.pdf. Accessed 12 May 2018.

64. Osteba Departamento de Sanidad del Gobierno Vasco. Guía de Evaluación Económica en el Sector Sanitario. Vitoria-Gasteiz: Gobierno Vasco: Departamento de Sanidad. Dirección de Planificación y Evaluación Sanitaria; 1999. http://www.euskadi.eus/ contenidos/informacion/osteba_formacion_/eu_def/adjuntos/ economiaSanitaria.pdf. Accessed 12 May 2018.

65. The Dental and Pharmaceutical Benefits Agency (TLV). General guidelines for economic evaluations from The Dental and Pharmaceutical Benefits Agency. Stockholm; 2003. https://www. ispor.org/PEguidelines/source/Guidelines_in_Sweden.pdf. Accessed 12 May 2018.

66. National Institute for Health and Clinical Excellence. Guide to the methods of technology appraisal. London; 2014. http://www. nice.org.uk/article/pmg 19/resources/non-guidance-guide-to-theprocesses-of-technology-appraisal-pdf. Accessed 12 May 2018.

67. Smith DH, Gravelle H. The practice of discounting in economic evaluations of health care interventions. Int $\mathrm{J}$ Technol Assess Health Care. 2001;17:236-43.

68. Paulden M, Claxton K. Budget allocation and the revealed social rate of time preference for health. Health Econ. 2012;21:612-8.

69. Attema AE, Bleichrodt H, L'Haridon O, Peretti-Watel P, Seror V. Discounting for health and money: a field experiment using the direct method. J Risk Uncertain. 2018. https://doi.org/10.1007/ s11166-018-9279-1.

70. Attema AE, Versteegh MM. Would you rather be ill now, or later? Health Econ. 2013;22:1496-506.

71. Attema AE, Brouwer WBF. A test of independence of discounting from quality of life. J Health Econ. 2012;31:22-34.

72. van der Pol M, Cairns J. Estimating time preferences for health using discrete choice experiments. Soc Sci Med. 2001;52:1459-70.

73. Cairns J. Health, wealth and time preference. Proj Apprais. 1992;7:31-40.

74. Cairns JA, Van Der Pol MM. The estimation of marginal time preference in a UK-wide sample (TEMPUS) project. Health Technol Assess. 2000;4:1-83 (i-iv).

75. Cairns JA. Valuing future benefits. Health Econ. 1994;3:221-9.

76. Cropper M, Aydede SK, Portney PR. Rates of time preference for saving lives. Am Econ Rev. 1992;82:469-72.

77. Robberstad B. Estimation of private and social time preferences for health in northern Tanzania. Soc Sci Med. 2005;61:1597-607.

78. Olsen JA. Time preferences for health gains: an empirical investigation. Health Econ. 1993;2:257-65.

79. Gyrd-Hansen D. Comparing the results of applying different methods of eliciting time preferences for health. Eur $\mathrm{J}$ Health Econ. 2002;3:10-6.

80. Lazaro Alquezar A, Barberan R, Rubio E. Private and social time preferences for health and money: an empirical estimation. Health Econ. 2001;10:351-6.

81. Paulden M, Galvanni V, Chakraborty S, Kudinga B, McCabe C. Discounting and the evaluation of health care programs. 2016. https://www.cadth.ca/sites/default/files/pdf/CP0008_Economic_ 
Evaluation_Guidelines_Discount_Rate_Report.pdf. Accessed 12 May 2018.

82. Bleichrodt H, Gao Y, Rohde KIM. A measurement of decreasing impatience for health and money. J Risk Uncertain. 2016;52:213-31.
83. Attema AE, Bleichrodt H, Gao Y, Huang Z, Wakker PP. Measuring discounting without measuring utility. Am Econ Rev. 2016;106:1476-94.

84. Pigou AC. The economics of welfare. London: McMillan \& Co.; 1920. 